\title{
Riesgo de transmisión de enfermedades infecciosas en la clínica dental
}

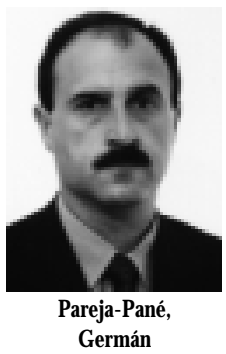

\section{Risk of transmission of infectious diseases in dental-care settings}

Pareja- Pané, Germán

Profesor asociado. Unidad de Odontología Preventiva y Comunitaria. Facultad de Odontología. Universidad de Barcelona.

\begin{abstract}
Resumen
Se presenta en este artículo una revisión del riesgo de transmisión de enfermedades infecciosas en la clínica dental. Las hepatitis víricas, en especial la hepatitis B y la C, la infección por el virus de la inmunodeficiencia humana, la tuberculosis, y otras enfermedades infecciosas pueden ser potencialmente transmitidas en el ejercicio de la profesión, tanto a los pacientes como a los profesionales. El conocimiento de la probabilidad de transmisión y sus características son la base sobre la que desarrollarán las medidas preventivas de control de infección que intentan evitar o por lo menos minimizar la probabilidad de adquirir estas enfermedades en el ámbito laboral.
\end{abstract}

Palabras clave: Enfermedades infecciosas, Hepatitis, VIH, Tuberculosis, Odontología.

\begin{abstract}
In this paper, we present a review of the risk of transmission of infectious diseases and its implications for dentistry. Hepatitis, specially hepatitis B and C, HIV infection, tuberculosis and other infectious diseases can be potencially transmitted in dental-care settings affecting both patients and the dental staff. Knowing the transmission probability and its features is the basis for the development of preventive infection control measures, in order to try to avoid or at least minimize the probability of acquiring these diseases in the working environment.
\end{abstract}

Key words: Infectious diseases, Hepatitis, HIV, Tuberculosis, Dentistry.

\begin{tabular}{ccc}
\hline Fecha recepción & Fecha última revisión & Fecha aceptación \\
$29-03-2204$ & $15-04-2004$ & $22-04-2004$ \\
\hline
\end{tabular}

BIBLD [1138-123X (2004)9:3; mayo-junio 257-360]

Pareja-Pané G. Riesgo de transmisión de enfermedades infecciosas en la clínica dental RCOE 2004;9(3):313-321.

\section{Correspondencia \\ Germán Pareja Pané \\ Odontología Preventiva y Comunitaria \\ Facultad de Odontología \\ C/ Feixa Larga, $\mathrm{s} / \mathrm{n}$ \\ 08907 L'Hospitalet de Lobregat \\ (Barcelona) \\ e-mail: gpareja@ub.edu}




\section{Introducción}

En la práctica clínica, los profesionales de la odontología están expuestos a una amplia variedad de microorganismos capaces de causar enfermedad. El uso de instrumentos punzantes o cortantes y el contacto con fluidos orgánicos potencialmente contaminados conllevan, como en otras especialidades médicas y quirúrgicas, un riesgo de transmisión de infecciones al personal clínico y al paciente. Cuando se compara la incidencia de ciertas enfermedades infecciosas se observa que es mayor en los odontólogos-estomatólogos que en el resto de la población y hay casos documentados de transmisión de estas enfermedades en el ámbito dental. La mayoría de estos microorganismos transmisibles son virus y en menor medida bacterias. Algunos motivan infecciones leves como el resfriado común, otros pueden originar cuadros clínicos tan graves como el SIDA.

Los mecanismos de transmisión de estos agentes microbianos en la práctica profesional se resumen y exponen a continuación:

1. Contacto directo con lesiones, sangre, fluidos orales y secreciones nasorespiratorias contaminadas.

2. Contacto indirecto con instrumentos, superficies y equipos dentales contaminados.

3. Salpicaduras de sangre, saliva o secreciones nasorespiratorias directamente a la piel o las mucosas.

4. Transmisión aérea a través de microgotas que se generan al hablar, toser o en el acto quirúrgico y que contienen sangre o secreciones contaminadas.
La infección por estos patógenos, independientemente de la ruta de transmisión que sigan, requiere la presencia de una serie de condiciones comúnmente conocidas como «cadena de infección». En primer lugar debe existir un huésped susceptible que es quien va a ser infectado. En segundo lugar, el microorganismo patógeno debe estar en cantidad y virulencia suficientes para poder causar infección. Y por último, debe haber una puerta de entrada que permita a este microorganismo ponerse en contacto con el huésped. Cada uno de estos eslabones de la cadena debe ser tenido en cuenta a la hora de evaluar la probabilidad de que estos microorganismos consigan su objetivo y a su vez constituyen las bases sobre las que se asentaran todos aquellos procesos o técnicas tendentes a minimizar este riesgo.

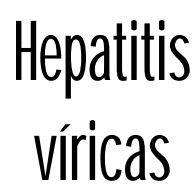

Las hepatitis víricas son enfermedades inflamatorias del hígado causadas por virus. Se conocen, por el momento, cinco virus identificados como responsables y denominados con las primeras letras del alfabeto: A, B, C, D, E y G. La importancia de estas enfermedades para el odontólogo-estomatólogo radica en que algunas de ellas se pueden trasmitir en la práctica profesional. Además, su distribución es universal, la morbilidad y mortalidad son significativas y disponemos, en algunas de ellas, de medidas específicas de protección como las vacunas ${ }^{1 *}$.

\section{Hepatitis A}

La hepatitis A la causa un virus ARN, el virus de la hepatitis $A$ (VHA) que se transmite a través de alimentos y aguas contaminadas con residuos fecales. Su mecanismo de transmisión es oro-fecal predominantemente y aunque se ha observado su presencia en sangre de individuos infectados y está documentada su transmisión en transfusiones sanguíneas, la transmisión percutánea por sangre o instrumentos contaminados, aunque posible, resulta extremadamente rara.

Es una enfermedad que suele tener un curso benigno (rara vez es mortal) y no evoluciona a la cronicidad. Su distribución es universal y afecta principalmente a niños en quienes causa una enfermedad leve o asintomática. Su prevención se consigue fundamentalmente con la mejora de las condiciones higiénico-sanitarias, en especial de los alimentos y las aguas potables. Disponemos asimismo de medidas de protección específica: una inmunoglobulina anti-VHA y, desde 1995, una vacuna segura y altamente efectiva.

La vacunación del odontólogo-estomatólogo y del personal auxiliar no está indicada excepto en áreas con altas tasas de prevalencia de la enfermedad², pues el riesgo de contraer la enfermedad en el ámbito laboral es muy bajo ${ }^{3}$.

\section{Hepatitis B}

La infección por el virus de la hepatitis B (VHB) es la causa más importante de hepatitis aguda y crónica, de cirrosis hepática y de carcinoma hepatocelular. Se trata de un virus ADN amplia y universalmente distribuido.

La infección por el virus de la hepatitis B determina la aparición en la 
sangre de diferentes sistemas antígeno-anticuerpo denominados marcadores serológicos de la hepatitis $B$. Aparecen secuencialmente y de manera ordenada y su estudio permite el diagnóstico de la enfermedad y la identificación del estado de la infección en un momento determinado. El antígeno de superficie (HBsAg) se encuentra en la envoltura superficial del virus y se le conoce también como antígeno «Australia» por ser el primer marcador serológico de la hepatitis $B$ descubierto en el suero de un aborigen australiano. El anticuerpo anti-antígeno de superficie (anti-HBs) aparece en respuesta a la infección para neutralizar al HBsAg y es responsable de la inmunidad a la enfermedad a largo plazo. El anti-HBc, el anticuerpo anti-antígeno del core (una estructura interna del virus) aparece en todas las infecciones por el VHB y persiste casi indefinidamente; se utiliza, a menudo y por esta última característica, como indicador de infección antigua o pasada. El sistema HBe se relaciona con la replicación del virus y la infectividad. La presencia del anticuerpo anti-antígeno «e» (anti-HBe) se correlaciona con una baja capacidad infectiva.

Las personas que por vacunación o por infección previa poseen anticuerpos frente al virus, presentan, ante un nuevo contacto, una respuesta anamnésica que lo neutraliza. En personas no inmunizadas, un primer contacto con el virus puede dar lugar a la neutralización de éste o al desarrollo de una infección aguda. La infección aguda puede cursar clínicamente como una hepatitis aguda o bien de un modo inaparente (formas asintomáticas o subclínicas). La clínica de la infección aguda incluye diferentes combinaciones de signos y síntomas como ictericia, dolor abdominal, nauseas, vómitos, anorexia, etc. Una forma clínica especialmente grave es la hepatitis fulminante, que se caracteriza anatomopatológicamente por una destrucción masiva de las células hepáticas. Afortunadamente su incidencia no es alta $(0,5 \%-1 \%$ de las infecciones agudas) porque en una proporción muy alta de los enfermos causa la muerte. Las formas fulminantes parecen estar en relación con una respuesta inmune exagerada.

La gran mayoría de las infecciones agudas se resuelven espontáneamente y no dejan secuelas. Sin embargo, algunas infecciones agudas se cronifican y dan lugar a hepatopatías crónicas con sus secuelas de cirrosis hepática y cáncer de hígado o al estado de portador crónico sano. Un portador crónico sano, se define como aquel paciente que es positivo al antígeno de superficie $(\mathrm{HBsAg}+$ ) al menos en dos ocasiones y con un intervalo entre ambas de seis meses como mínimo. La detección de la infección crónica es de suma importancia debido a sus graves consecuencias. La magnitud y severidad del problema es enorme desde una óptica mundial, aunque en España la enfermedad tenga una endemicidad baja (menos del 1\%de la población es portadora) ${ }^{4}$. En el mundo, más de 300 millones de personas son portadores crónicos.

Los estudios epidemiológicos demuestran que algunos colectivos humanos presentan un riesgo de infección superior al de la población general y son, por tanto, grupos de riesgo. Entre ellos y formando parte del personal sanitario que trabaja en contacto con sangre, los odontólogos-estomatólogos y el personal dental auxiliar. En diversos estudios que comparan la prevalencia de hepatitis $B$ en personal dental respecto a la población general, se observa que la prevalencia de marcadores serológicos de infección pasada (anti-HBs y anti-HBc) es más elevada y que la tasa anual de hepatitis $B$ es superior a la estimada para la población general.

La transmisión de la hepatitis $B$ a pacientes atendidos por profesionales sanitarios infectados está documentada desde hace tiempo y el riesgo de transmisión del VHB de trabajadores sanitarios a pacientes a través de procedimientos médicos, quirúrgicos o dentales es superior al del VIH. Se han descrito e investigado episodios de transmisión del VHB de trabajadores sanitarios a pacientes, con fallecimiento de algunos de ellos y transmisión secundaria a familiares. En estos procedimientos frecuentemente se habían producido infracciones graves de las medidas de control de infección.

La disminución de la prevalencia de la hepatitis por VHB en los profesionales sanitarios en los últimos años es consecuencia de la adopción generalizada de medidas de control de la infección y de la introducción de la vacunación frente a este virus en el colectivo de los trabajadores sanitarios; ambas medidas han demostrado ser muy eficaces. El antígeno de superficie (HBsAg) es el componente de la vacuna e induce la producción de anticuerpos neutralizantes del VHB (anti-HBs). La vacunación es segura y altamente efectiva. Confiere protección a más del $90 \%$ de los individuos vacunados ${ }^{5}$ aunque la respuesta inmu- 
nológica a la vacuna es menor en ancianos, pacientes inmunocomprometidos y obesos. En el personal sanitario es aconsejable practicar una analítica a los dos meses de completar la vacunación para determinar la adecuación de la respuesta inmunológica. En estudios a largo plazo en individuos que respondieron positivamente a la vacunación se observó una disminución de los títulos protectores de anti-HBs por debajo de $10 \mathrm{UI} / \mathrm{L}$, que es el umbral considerado como óptimo, entre los 5 y los 11 años de la vacunación. A pesar de ello, ninguno de estos individuos desarrolló una infección crónica por el VHB aunque algunos pocos presentaron infecciones agudas por el VHB en general subclínicas y poco severas 6 . Al parecer, hay una memoria inmunológica que pone en marcha, a pesar de los bajos títulos de anti-HBs, una respuesta anamnésica que neutraliza al virus. Por este motivo, no se recomiendan dosis de recuerdo de la vacuna en aquellos individuos que respondieron positivamente a la vacunación.

\section{Hepatitis C}

La infección por el virus de la hepatitis C (VHC) causa enfermedad hepática que puede cursar clínicamente o hacerlo de modo inaparente. Un $70-80 \%$ de los pacientes no presentan sintomatología y por tanto desconocen que padecen o han padecido la enfermedad. Durante la infección aguda puede darse una hepatitis fulminante como en el caso de la hepatitis $B$ pero no es tan frecuente. Se cronifica con más facilidad que la hepatitis B (aproximadamente un 60\% de casos). De estas hepatitis crónicas un $20 \%$ van a desarrollar una cirrosis hepática y algunos un carcinoma hepatocelular. Esta incapacidad para eliminar el virus y en consecuencia cronificar la enfermedad, es el resultado de su alta capacidad mutagénica que le hace escapar de la detección por el sistema inmune. Por consiguiente, la aparición de anticuerpos neutralizantes tras la infección aguda ofrece poca o ninguna protección ${ }^{7}$.

La infección se encuentra en el 0,5-8\% de los donantes voluntarios de sangre. Su transmisión es parenteral y se presenta con más frecuencia después de una transfusión sanguínea y en usuarios de drogas por vía parenteral (UDVP) que comparten jeringuillas. No esta clara la transmisión sexual y intrafamiliar. El virus se ha detectado en la saliva en más del $50 \%$ de pacientes con infección aguda o crónica ${ }^{8}$ y está documentada la transmisión después de una mordida humana. Los estudios acerca del riesgo laboral de adquirir la enfermedad en personal dental no son concluyentes y muestran diferencias probablemente debidas al tamaño de la muestra y al diseño de los estudios y por tanto se necesita más investigación. La incidencia de seroconversión en trabajadores sanitarios después de un pinchazo accidental oscila entre el 0-10\%.

Existe escasísima evidencia de transmisión de VHC desde un trabajador sanitario infectado a sus pacientes ${ }^{10}$. Se han documentado casos de hepatitis $C$ adquirida en centros sanitarios en relación con procedimientos diagnósticos o terapéuticos en pacientes atendidos por personal sanitario infectado. En algunos de estos casos se puede considerar que se habían incumplido las medidas de prevención para evitar la transmisión cruzada entre enfermos y que se había favorecido involuntariamente la difusión de la infección.

\section{Hepatitis D}

La hepatitis $D$ o delta la causa un virus ARN defectivo, el virus de la hepatitis $D(V H D)$, que requiere la presencia del virus de la hepatitis B (VHB) para su expresión y replicación. Existen, por tanto, únicamente dos vías para que pueda manifestarse: por infección simultánea con el virus de la hepatitis B (co-infección VHD-VHB); o por infección posterior en un individuo portador previo del VHB (sobreinfección). Las sobreinfecciones se asocian con un riesgo altísimo de desarrollar una hepatitis crónica y posteriormente una cirrosis hepática. Las co-infecciones se asocian con una alta ocurrencia de hepatitis fulminante y un riesgo bajo de desarrollar una hepatitis crónica.

El virus de la hepatitis $D(V H D)$ se transmite parenteralmente por vía percutánea o permucosa y la mayoría de los casos están documentados en drogadictos y hemofílicos que han recibido hemoderivados. Puesto que padecer una hepatitis $D$ depende de la presencia del virus de la hepatitis $B$ (VHB), las intervenciones sanitarias destinadas a evitar la transmisión del VHB, en especial la vacunación de la hepatitis B, son la mejor estrategia preventiva frente a la transmisión del virus de la hepatitis $D$. La vacunación de la hepatitis $B$ y la inmunización pasiva con inmunoglobulina específica anti-hepatitis $B$ confieren protección frente a la co-infección HDV-HBV. No existe, en la actualidad, ningún modo específico de evitar la sobreinfección por HDV en portadores crónicos de la hepatitis $B$. La probabilidad de pade- 
cer la enfermedad en profesionales y personal auxiliar es baja.

\section{VIH}

El VIH se transmite por vía parenteral. La fuente principal de infección es la sangre y sus derivados de aquellos individuos que son seropositivos. El virus también se encuentra en otros fluidos orgánicos y entre ellos la saliva, aunque con poca concentración ${ }^{11}$ y por tanto la transmisión vía secreciones orales se considera poco relevante.

La magnitud del riesgo de transmisión del virus de la inmunodeficiencia humana al personal sanitario en general y en concreto al personal dental puede ser examinada de diferentes maneras: 1) en estudios de seroprevalencia del HIV en personal sanitario; 2) en estudios de seroconversiones documentadas o probables en trabajadores sanitarios después de una exposición laboral; 3) en estudios prospectivos de personal sanitario que ha sufrido una exposición laboral ${ }^{12}$.

\section{Estudios de seroprevalencia}

Hay pocas diferencias en los porcentajes de seropositividad si comparamos los trabajadores sanitarios con aquellos que no lo son. De hecho la mayoría de seropositivos presentan factores de riesgo reconocidos como relaciones homosexuales, usuarios de drogas por vía intravenosa, etc. y en el grupo de aquellos que no presentan ninguno de estos factores de riesgo no hay una proporción significativa de trabajadores sanitarios.

\section{Estudios de seroconversiones documentadas}

Las seroconversiones documentadas en trabajadores sanitarios se clasi- fican en confirmadas y probables. Las seroconversiones confirmadas son las que cumplen los siguientes criterios: 1) ha habido una exposición laboral a un paciente con infección conocida por el $\mathrm{VIH}$; 2) dentro de los primeros días después de la exposición el trabajador sanitario presenta un test al $\mathrm{VIH}$ negativo; 3) posteriormente el test al VIH hace positivo; 4) no existen otros factores de riesgo. De estos casos confirmados la mayoría son enfermeras o técnicos de laboratorio. No hay ningún caso confirmado en dentistas o en personal dental. Las seroconversiones probables son aquellos casos que no cumplen los criterios anteriores pero que se sospecha que el virus ha sido transmitido en el lugar de trabajo. Entre estos casos hay descrito un dentista de Nueva York sin otros factores de riesgo conocidos y que probablemente adquirió la infección en el desempeño de su trabajo ${ }^{13}$.

\section{Estudios prospectivos}

Los estudios prospectivos analizan que porcentaje de seroconversiones ocurre después que un trabajador sanitario sufra una exposición ocupacional. El más citado de todos ellos, realizado en los Centros para el Control de Enfermedad (CDC) de los Estados Unidos pero que recoge casos de otros países, registra por el momento cuatro seroconversiones en aproximadamente 1100 trabajadores sanitarios con exposiciones percutáneas. A modo de resumen, estos estudios realizados durante más de 10 años en Europa y los Estados Unidos han cuantificado este riesgo de seroconversión en aproximadamente 0,33\% después de una exposición percutánea ${ }^{14}$. El riesgo de seroconversión tras una exposición mucocutánea es aun menor (aproximadamente un 0,09\%) ${ }^{15}$.

Tras más de 15 años de experiencia y de millones de procedimientos realizados, únicamente se ha descrito un caso documentado de transmisión del HIV de un trabajador sanitario portador del VIH a seis de sus pacientes ${ }^{16}$. El modo exacto de esta transmisión, sin embargo, permanece desconocido. El seguimiento, por los CDC (Centers for Disease Control) de Atlanta (EE.UU.) de más de 22.000 pacientes tratados por 63 profesionales sanitarios portadores del VIH (incluyendo 33 dentistas) no ha demostrado transmisión del $\mathrm{VIH}$ a través de procedimientos médicos, quirúrgicos o dentales. El estudio de pacientes con SIDA sin factores de riesgo identificados tampoco ha implicado a profesionales sanitarios portadores del VIH como origen de su infección ${ }^{17}$.

En conclusión, la evidencia que suministra la literatura científica y la experiencia de bastantes años de epidemia de infección por VIH, permiten afirmar que el riesgo de transmisión del VIH de un trabajador sanitario a un paciente en el ejercicio de su práctica profesional es remoto, y no justifica en absoluto el que pudiese realizarse un cribado serológico del personal sanitario como teórica medida de protección de los pacientes.

\section{Tuberculosis}

La vía de transmisión de la tuberculosis es aérea, por inhalación de partículas procedentes de las secreciones respiratorias que contienen bacilos tuberculosos. Estas partículas proceden de enfermos que eliminan 
bacilos en sus secreciones respiratorias y que al toser, hablar o estornudar generan aerosoles, diminutas gotas que permanecen en suspensión en el aire y que son susceptibles de ser inhaladas por otros individuos, alcanzar los alvéolos pulmonares y transmitir la enfermedad. La vulnerabilidad del bacilo a la radiación ultravioleta hace difícil la transmisión en espacios abiertos o en locales iluminados por luz natural y bien ventilados. De hecho, los porcentajes más elevados de transmisión se encuentran entre los contactos próximos al enfermo que comparten su dormitorio (familiares, instituciones cerradas como cárceles, residencias de ancianos, hospitales para enfermos mentales, etc.). El estudio de contactos en el lugar de trabajo y en contactos ocasionales ha demostrado niveles muy bajos de transmisión ${ }^{18^{*}}$.

La probabilidad de que una persona se infecte depende de la concentración de partículas infecciosas en suspensión en el aire, de factores ambientales y de las características del individuo fuente de la infección y su proceso patológico. Entre las causas ambientales cabe destacar el contacto entre individuos susceptibles y enfermos de tuberculosis en espacios pequeños y cerrados, una ventilación inadecuada que causa una menor dilución en el aire de estas partículas y una menor eliminación, y la recirculación del aire que las contiene. La mayor infectividad de un enfermo está relacionada con el número de microorganismos que expele al exterior y esto a su vez de la localización anatómica de la enfermedad, la presencia de tos o de otras maniobras que fuerzan al enfermo a lanzar al exterior secreciones con material infeccioso, la capacidad del enfermo de taparse la boca cuando tose, la existencia de lesiones pulmonares cavitadas, la duración del tratamiento antituberculoso, etc. Es mayor la capacidad infectiva de un enfermo que no ha recibido tratamiento que la de quien ha recibido un tratamiento adecuado y en general cuanto mayor es el tiempo de tratamiento, menor es la infectividad.

La transmisión de la tuberculosis en las instalaciones sanitarias es un hecho conocido. La magnitud de este riesgo depende del tipo de instalación sanitaria, de la población atendida, del tipo de intervención sanitaria que se lleva a cabo y de la categoría del personal sanitario. La transmisión nosocomial de la tuberculosis se asocia con el contacto próximo con pacientes tuberculosos y con procedimientos como la broncoscopia, la intubación endotraqueal y ventilación mecánica, la irrigación de abcesos abiertos y las autopsias. Los procedimientos que estimulan la tos y el tratamiento con aerosoles comportan también un mayor riesgo.

Ciertos procedimientos dentales como las preparaciones cavitarias con instrumental rotatorio, especialmente a alta velocidad, generan aerosoles detectables en el aire ambiental. Cuando estos procedimientos se realizan en enfermos de tuberculosis cabe la posibilidad de que estas partículas en suspensión contengan bacilos tuberculosos que pueden infectar al personal sanitario. Parece, sin embargo, que el riesgo de transmisión al personal que trabaja en clínicas dentales es bajo, parecido al de la población general ${ }^{19}$. No parece que la tuberculosis se trans- mita con más frecuencia en las consultas dentales. No hay, sin embargo, demasiados estudios que confirmen o rebatan estos hechos y probablemente se necesita más investigación. Se impone la cautela y puesto que algunas intervenciones dentales son propicias para generar aerosoles que podrían contener material contaminado y por tanto existe posibilidad de transmisión, sería necesaria la aplicación de medidas preventivas que la reduzcan o eliminen.

\section{Infecciones respiratorias}

Muchos de los organismos responsables de infecciones del tracto respiratorio se han detectado en los aerosoles dentales. Se ha observado también una correlación positiva entre la incidencia de ciertas enfermedades respiratorias en pacientes, como el resfriado común y la gripe, y la salud del personal que los atiende. Se deduce de ello que el personal dental tiene un riesgo, al menos potencial, de enfermar de una enfermedad respiratoria como el resfriado común, la gripe, etc.

\section{Otras infecciones}

Se han señalado otras enfermedades infecciosas como potencialmente transmisibles en el ámbito dental. El virus de la varicela-herpes zoster (VZV) se transmite por vía aérea y es el causante de la varicela y del herpes zoster cuando se reactiva años después. Puede causar malformaciones fetales graves en hijos de mujeres seronegativas que adquieren la infección en el

RCOE, 2004, Vol 9, №3, 313-321 
embarazo. El virus de Epstein-Barr (VEB), causante de la mononucleosis infecciosa y el citomegalovirus (CMV), se transmiten también por vía aérea. La infección por este último virus es frecuente en inmunodeprimidos, en especial en aquellos afectados por el síndrome de inmunodeficiencia adquirida y causa también malformaciones congénitas fetales graves si se transmite a mujeres embarazadas que no hayan estado en contacto con él. Otras enfermedades infecciosas de la infancia como la rubéola se transmiten por vía aérea y son susceptibles de ser adquiridas por trabajadores sanitarios no inmunizados ${ }^{20}$. El virus del herpes simple ( $\mathrm{HVH}-\mathrm{I}$ y $\mathrm{HVH}-\mathrm{II})$ causa abcesos digitales y queratoconjuntivitis herpéticas, que se dan con cierta frecuencia en trabajadores sanitarios.

\section{Encefalopatías espongiformes transmisibles}

Las encefalopatías espongiformes transmisibles (EET) son un grupo de enfermedades que afectan al hombre y a algunos animales. Anatomopatológicamente, se caracterizan por la formación de vacuolas microscópicas en la substancia gris del cerebro que le dan un aspecto característico de esponja. Afectan al sistema nervioso central y dan signos y síntomas neurológicos. Se transmiten por vía oral y parenteral y tienen un periodo de incubación muy largo.

Durante un tiempo se pensó que eran enfermedades degenerativas y se especuló sobre su origen autoinmune. Se las llamó incluso enfermedades cau- sadas por virus lentos porque se pensaba que el agente etiológico era un virus no identificado con características especiales. Hoy día, se sabe que la causa de estas enfermedades son los priones. Los priones son partículas infecciosas de naturaleza proteica que a diferencia del resto de agentes infecciosos como los virus o las bacterias, no disponen de material genético. Son una isoforma anormal de una glicoproteína celular que se conoce como PrP. En el hombre, esta proteína priónica normal (PrP o proteína resistente a la proteasa) está codificada por un gen en el cromosoma 20; el producto de este gene es soluble y resistente a la proteasa (PrPsens) y no representa ningún peligro para la salud. Sin embargo, en las encefalopatías espongiformes hereditarias hay una mutación en este gen que codifica entonces una proteína PrP anormal que es insoluble y resistente a la proteasa y que es letal para el tejido neuronal. En las encefalopatías espongiformes de naturaleza adquirida el organismo adquiere por transmisión una proteína priónica anormal que actúa como catalizador en la generación de más proteínas priónicas anormales que finalmente conducen a la enfermedad ${ }^{21}$.

Las encefalopatías espongiformes transmisibles afectan a humanos y a animales. Entre las encefalopatías espongiformes transmisibles animales más importantes se encuentra el «scrapie» que afecta al ganado ovino y caprino y que es conocida desde el siglo XVIII; la encefalopatía transmisible del visón que afecta a estos animales alimentados con desperdicios de ganado ovino y bovino; la enfermedad caquectizante crónica que afecta a ciervos y alces; y la encefalo- patía espongiforme bovina o enfermedad de las vacas locas y enfermedades relacionadas como la encefalopatía espongiforme felina, la encefalopatía espongiforme ovina y las encefalopatías espongiformes experimentales. Estas cuatro enfermedades se agrupan en un apartado denominado encefalopatías espongiformes británicas por su probable origen común. La encefalopatía espongiforme bovina apareció por primera vez en Gran Bretaña en 1986 convirtiéndose rápidamente en una epidemia con un pico máximo de casos en 1992. Desde Gran Bretaña se extendió al resto de Europa y en España los primeros casos se detectaron en el 2000. Hasta 1994 se habían detectado en el mundo unos 148.000 casos aproximadamente, la gran mayoría de los cuales en Gran Bretaña (146.760 casos). Desde 1995 se han diagnosticado unos 40.000 casos $^{22}$, observándose una tendencia epidemiológica a la disminución en la incidencia. Al parecer esta enfermedad está en relación con la alimentación del ganado bovino con piensos fabricados con restos de animales de otras especies (despojos infecciosos conocidos como harinas de carne y hueso).

Las encefalopatías espongiformes transmisibles en humanos pueden presentarse en forma esporádica, familiar o adquirida. Las formas hereditarias o familiares son todas de transmisión autosómica dominante y entre ellas se encuentra el insomnio familiar fatal, el síndrome de Gertsmann-Straussler-Scheinher y la enfermedad de Creutzfeldt-Jacob familiar. La forma esporádica se conoce como enfermedad de Creutzfeldt-Jacob esporádica, es la más frecuente de 
todas las encefalopatías espongiformes transmisibles humanas (con una incidencia aproximada de un caso por millón de habitantes y año) y se desconoce su etiología. Las formas adquiridas incluyen el kuru que afecta a individuos de Papua Nueva Guinea y que está relacionada con prácticas caníbales; la enfermedad de Creutzfeldt-J akob yatrogénica originada por la exposición a tejidos o instrumental contaminados con el agente de la forma esporádica de la enfermedad de Creutzfeldt-Jakob la mayoría de los cuales se corresponden a niños tratados con hormona del crecimiento procedente de hipófisis de cadáveres humanos; y la variante de la enfermedad de Creutzfeldt-Jakob.

En marzo de 1996 el gobierno británico anunció la aparición de diez casos atípicos de la enfermedad de Creutzfeldt-Jakob y su posible vínculo con la encefalopatía espongiforme bovina. La primera notificación de un caso de la enfermedad es de 1989, cuatro años después del inicio de la epizootia de encefalopatía espongiforme bovina. La relación entre encefalopatía bovina y la humana se estableció en virtud de una serie de coin- cidencias histopatológicas y experimentales y estos casos de enfermedad de Creutzfeldt-Jakob atípicos pasaron a denominarse «variante de la enfermedad de Creutzfeldt-J akob».

A diferencia de la enfermedad de Creutzfeldt-Jakob yatrogénica o esporádica, la variante de la enfermedad de Creutzfeldt-J akob (VEC) empieza típicamente con depresión o profunda ansiedad y otros síntomas neurológicos que duran semanas o meses y que acaban en demencia y otros trastornos, y finalmente la muerte. En España, hasta la fecha, no se han notificado casos confirmados o probables de vECJ. Desde 1993, bajo sospecha de otros diagnósticos, se han notificado al Registro Español de Encefalopatías Espongiformes Transmisibles Humanas cuatro pacientes que cumplen criterios de vECJ posible ${ }^{23^{* *}}$.

A pesar de las dificultades para estimar el riesgo de vECJ en España, la expectativa de aparición de casos de vECJ en nuestro país en el futuro es cada vez menos incierta. Dada la gran diferencia en exposición acumulada a materiales de riesgo entre la población de Gran Bretaña y la española, la probabilidad de aparición de casos de
vECJ en los próximos años parece baja. Por otro lado, la ausencia de casos de vECJ desde su comienzo, en 2002 y el reciente descenso en las defunciones por esta causa en el Reino Unido sugiere que la epidemia está en regresión.

Los priones causantes de las encefalopatías espongiformes transmisibles humanas se localizan característicamente en el cerebro y en la médula espinal. A diferencia del resto de enfermedades por priones, el agente causal de la vECJ se localiza también en el tejido linfático (amígdala faríngea, ganglios linfáticos y bazo) así como en las células nerviosas en todo el organismo. Los pacientes con encefalopatías espongiformes transmisibles son contagiosos, aunque parece que la enfermedad se transmite únicamente por contacto de sangre o tejidos con material contaminado, especialmente cerebro, médula y quizás tejido linfático. No hay casos documentados de transmisión de encefalopatías espongiformes transmisibles humanas en el ámbito dental y, por tanto, parece que el riesgo laboral de adquirir estas enfermedades o transmitirlas a los pacientes es muy bajo.

\section{Bibliografía recomendada}

Para profundizar en la lectura de este tema, el/los autor/es considera/an interesantes los artículos que aparecen señalados del siguiente modo: * de interés ** de especial interés.

1*. Gillcrist JA. Hepatitis viruses A, B, C, D, E and $\mathrm{G}$ : implications for dental personnel. $\mathrm{J}$ Am Dent Assoc 1999;130(4):509-20. Excelente revisión bibliográfica de las hepatitis víricas y sus implicaciones en odontología.

2. Centers for Disease Control and Prevention. Prevention of hepatitis A through active or passi- ve immunization: Recommendations of the advisory committee on immunization practices (ACIP). MMWR Recomm Rep 1999;48:137.

3. Fagan EA, Partridge M, Sowray JH, Williams R. Review of the herpesviruses and hepatitis $A$ : the potential hazards in dental care. Oral Surg
Oral Med Oral Pathol 1987;64(6):693-7.

4. Bruguera M, Sanchez Tapias JM. Epidemiología de la hepatitis B en España. Med Clin (Barc) 1990; 95:470-5.

5. Centers for Disease Control and Prevention. Immunization of health-care workers: Recommendations of the advisory committee 
on immunization practices (ACIP) and the hospital infection control practices advisory committee (HICPAC). MMWR Recomm Rep 1997:46:1-42.

6. Mahoney FJ, Stewart K, Hu H, Coleman P, Alter MJ. Progress toward the elimination of hepatitis $B$ virus transmission among health care workers in the United States. Arch Intern Med 1997; 157(22):2601-5.

7. Farci P, Alter HJ, Govindarajan S y cols. Lack of protective immunity against reinfection with hepatitis C virus. Science 1992;258(5079): 135-40.

8. Komiyama K, Moro I, Mastuda Y y cols. HCV in saliva of chronic hepatitis patients having dental treatment. Lancet 1991;338(8766):572-3.

9. Centers for Disease Control and Prevention. Recommendations for follow-up of healthcare workers after occupational exposure to hepatitis C virus. MMWR Morb Mortal Wkly Rep 1997;46(26):603-6.

10. Esteban JI, Gómez J, Martell M y cols. Transmission of Hepatitis C Virus by a Cardiac Surgeon. N Engl J Med 1996;334(9): 555-60.

11. Levy JA, Greenspan D. HIV in saliva. Lancet 198;2(8622):1248.

12. Barr CE, Miller LK, Lopez MR y cols. Recovery of infectious HIV-1 from whole saliva. $J$ Am Dent Assoc 1992;123(2):36-7.

13. Chamberland ME, Conley LJ, Bush TJ, Ciesielski
CA, Hammett TA, Jaffe HW. Health care workers with AIDS. National surveillance update. J Am Med Assoc 1991;266(24):3459-62.

14. Klein RS, Phelan JA, Freeman K y cols. Low occupational risk of human immunodeficiency virus infection among dental professionals. N Engl J Med 1988;318(2):86-90.

15. Ippolito G, Puro V, De Carli G. The risk of occupational human immunodeficiency virus infection in health care workers. Italian Multicenter Study. The Italian Study Group on Occupational Risk of HIV infection. Arch Intern Med 1993;153(12):1451-8

16. Robert LM, Chamberland ME, MD, Cleveland $\mathrm{JL}$ y cols. Investigations of patients of health care workers infected with HIV. The Centers for Disease Control and Prevention database. Ann Intern Med 1995;122(9):653-7.

17. Dooley SW, Castro KG, Hutton MD y cols. Guidelines for preventing the transmission of tuberculosis in health-care settings, with special focus on HIV-related issues. MMWR Recomm Rep 1990;39:1-29.

18*. Cleveland JL, Gooch BF, Bolyard EA, Simone PM y cols. TB infection control recommendations from the CDC, 1994: considerations for dentistry. United States Centers for Disease Control and Prevention. J Am Dent Assoc 1995;126(5):593-9.
Este artículo es una excelente revisión bibliográfica de la transmisión de la tuberculosis en centros dentales.

19. Glick M, Goldman HS. Viral infections in the dental setting: potential effects on pregnant HCWs. J Am Dent Assoc 1993;124(6):79-86.

20. Porter S, Scully G, Ridgway GL, Bell J. The human transmissible spongiform encephalopathies (TSEs): implications for dental practitioners. Br Dent J 2000;188(8):432-6.

21. Ministerio de Sanidad y Consumo. Situación de la encefalopatia espongiforme bovina (EEB) en el mundo. [fecha de acceso 20 de marzo de 2004] URL disponible en http://www.eeb.es/ pags/europa.htm.

22. Instituto de Salud Carlos III. Centro Nacional de Epidemiología. Grupo Español de Estudio y Vigilancia de Encefalopatias Espongiformes. Variante de la Enfermedad de Creutzfeldt-Jakob en España, 1992 - 2003. Boletín Epidemiológico Semanal 2002; 10(26):277-9.

23**. Centers for Disease Control and Prevention. Guidelines for Infection Control in Dental Health-care settings-2003. MMWR Recomm Rep 2003;52:1-6.

Últimas recomendaciones de los Centros de Control de Enfermedades de los EEUU en control de infección 